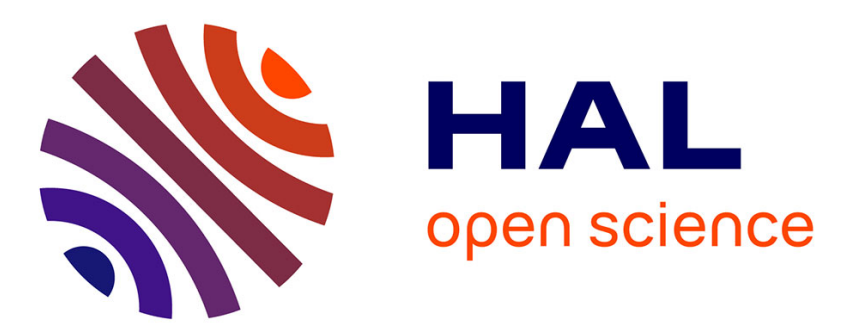

\title{
Geometric morphometrics reveals sexual and genotypic dymorphisms in the brown trout
}

Ghislaine Monet, Ayhan Uyanik, Alexis Champigneulle

\section{To cite this version:}

Ghislaine Monet, Ayhan Uyanik, Alexis Champigneulle. Geometric morphometrics reveals sexual and genotypic dymorphisms in the brown trout. Aquatic Living Resources, 2006, 19, pp.47-57. 10.1051/alr:2006004 . hal-02662152

\section{HAL Id: hal-02662152 \\ https://hal.inrae.fr/hal-02662152}

Submitted on 30 May 2020

HAL is a multi-disciplinary open access archive for the deposit and dissemination of scientific research documents, whether they are published or not. The documents may come from teaching and research institutions in France or abroad, or from public or private research centers.
L'archive ouverte pluridisciplinaire HAL, est destinée au dépôt et à la diffusion de documents scientifiques de niveau recherche, publiés ou non, émanant des établissements d'enseignement et de recherche français ou étrangers, des laboratoires publics ou privés.

$$
\text { Copyright }
$$




\title{
Geometric morphometrics reveals sexual and genotypic dimorphisms in the brown trout
}

\author{
Ghislaine Monet ${ }^{1, a}$, Ayhan Uyanik ${ }^{2}$ and Alexis Champigneulle ${ }^{1}$ \\ ${ }^{1}$ Institut National de la Recherche Agronomique, Centre alpin de recherche sur les réseaux trophiques des écosystèmes limniques, \\ Station d'Hydrobiologie lacustre, BP 511, 74203 Thonon-les-bains Cedex, France \\ 2 Université de Bretagne-Sud, Département de Mathématiques Informatique et Statistique, Campus de Tohannic BP 573, \\ 56017 Vannes Cedex, France
}

Received 11 July 2005; Accepted 14 November 2005

\begin{abstract}
The objective is to study different factors of variations in the body shape of trout (Salmo trutta) belonging to the Mediterranean lineage (indigenous trout) or Atlantic lineage (introduced trout), and their hybrids. Using thin plate-spline (TPS) method by pointing landmarks, it made possible to provide a graphical representation of the characteristic conformation of the individuals. The characteristics of form highlighted let appear - that the male trout have a dorsal part more prominent than that of the female trout and a larger head - the existence of a general curvature of the body related to the size of trout, independently of the sex. In addition, characteristics of form provide satisfactory results to distinguish the Mediterranean lineage from the Atlantic lineage. The recognition of hybrid trout is more random because very near to Mediterranean trout. The existence of a sexual dimorphism could be established in spite of the absence of information on the sex. Comparative with the sexual dimorphisms in spawning period reveals morphological transformations during the reproduction, mainly for the males. Independently of the genotypic and sexual dimorphisms, a general curvature of the body related to the size was detected.
\end{abstract}

Key words: Geometric morphometrics / Statistical shape analysis / Thin-plate spline (TPS) method / Atlantic trout, Mediterranean trout, Salmo trutta

Résumé - L'objectif est d'étudier différents facteurs de variations de forme chez la truite (Salmo trutta) appartenant au rameau évolutif méditerranéen autochtone, ou d'origine atlantique introduite, et de leurs hybrides. L'utilisation de la méthode des plaques minces (TPS) permet de représenter graphiquement les déformations des individus. Les caractéristiques de forme mises en évidence laissent apparaître - que les géniteurs mâles ont une partie dorsale plus proéminente que celle des géniteurs femelles et une plus grande tête - l'existence d'une courbure générale du corps liée à la taille des truites. Les caractéristiques de forme fournissent aussi des résultats satisfaisants pour distinguer la lignée «méditerranéenne » de la lignée « atlantique ». La reconnaissance des truites hybrides est plus aléatoire du fait de leurs ressemblances avec les truites méditerranéennes. L'existence d'un dimorphisme sexuel a pu être établi malgré l'absence d'informations sur le sexe. Une comparaison avec les dimorphismes sexuels en période de frai révèle des transformations morphologiques au moment de la reproduction, principalement chez les mâles. Indépendamment des dimorphismes génotypiques et sexuels, une courbure générale du corps liée à la taille a été détectée.

\section{Introduction}

To perform a shape analysis, a biologist traditionally selects distances between landmarks (such as lengths and widths), surface areas or angles between landmarks, and then submits these to a multivariate analysis (principal component analysis, discriminant function analyses, etc.). Geometric morphometrics don't work with ratios of distances or angles between landmarks but on the landmark coordinates directly, and provide a quantitative description, analysis and

\footnotetext{
a Corresponding author: monet@thonon.inra.fr
}

interpretation of variations in body shape observed in living creatures (Adams 2004). The reader will find technical description of geometric morphometrics and examples of applications in several published review of the topic (Cadrin 2000; Dryden 1999; Rohlf 1990; Rohlf and Marcus 1993).

This article will attempt to report the findings obtained during an exploratory use of geometrical methods to investigate body shape variations in the brown trout (Salmo trutta), either during spawning in the breeding season, or in the resident population present at the beginning of autumn.

We must stress that this study has been made on two distinct samples. A first group of trout "lineage" for which we 
know the lineage (Mediterranean, Atlantic, and hybrids) but not the sex, and a second group of trout "gender", composed of only one lineage Mediterranean, for which we have some information dealing with the sex. The first group "lineage" cannot be studied separately from the other because a distinction of trout according to the genotype could be potentially confused with a sexual dimorphism. Thus the interpretation made on the group "gender" will help us to interpret the results of the group "lineage". We investigated sexual dimorphism during the spawning stage. For the resident population, we investigated the influences of lineage (Mediterranean, Atlantic or hybrid) and of size.

\section{Materials and methods}

\subsection{Sampling}

\section{Local population}

The brown trout (Salmo trutta) were sampled during the month of September 1995. Sampling was carried out by electrical fishing amongst the population located in the Chevenne Brook and that in the main Dranse d'Abondance River, upstream and downstream of the inflow of the Chevenne Brook (Fig. 1). The development of genetic methods (enzyme polymorphism, DNA microsatellites etc.) has made it possible to detect a considerable degree of intraspecies genetic diversity within this zone in the brown trout, and the existence of two distinct lineages, the native Mediterranean lineage, introduced Atlantic fish, plus hybrids between these two.

The trout were anesthetized to prevent them from moving, and were then placed over a measuring scale and photographed (slides). Unlike the sample of spawners, the sex and stage of maturity of the individuals sampled from within the resident population were not known. A fraction of the adipose fin was collected, placed in absolute ethanol and then the nuclear DNA was analyzed in the laboratory. Three microsatellites (STR 541, STR 591 and STR 791) indicative of the lineage were analyzed (Largiader, unpublished data). In the text below, individuals in which all 6 alleles analyzed were of the Atlantic type are described as having the Atlantic genotype, individuals in which all 6 alleles analyzed were of the Mediterranean type are described as having the Mediterranean genotype, and individuals in which the 6 alleles analyzed contained a mix of both types of alleles are described as hybrid. The numbers of fish in each sampling stratum are summarized (Table 1).

\section{Migrant spawners}

The spawners were caught in November and December 1995, during the breeding season. The sampling was carried out by trapping migrants between the main Dranse d'Abondance River and the Chevenne Brook (Fig. 1). These trout were processed in the same way as the resident population. In addition, at this time of year, the sex of the mature fish could be identified with certainty by external methods. The mature males were identified by abdominal palpation to expel the milt. The mature females were identified on the basis of the dilatation of their abdomens and urogenital papillae

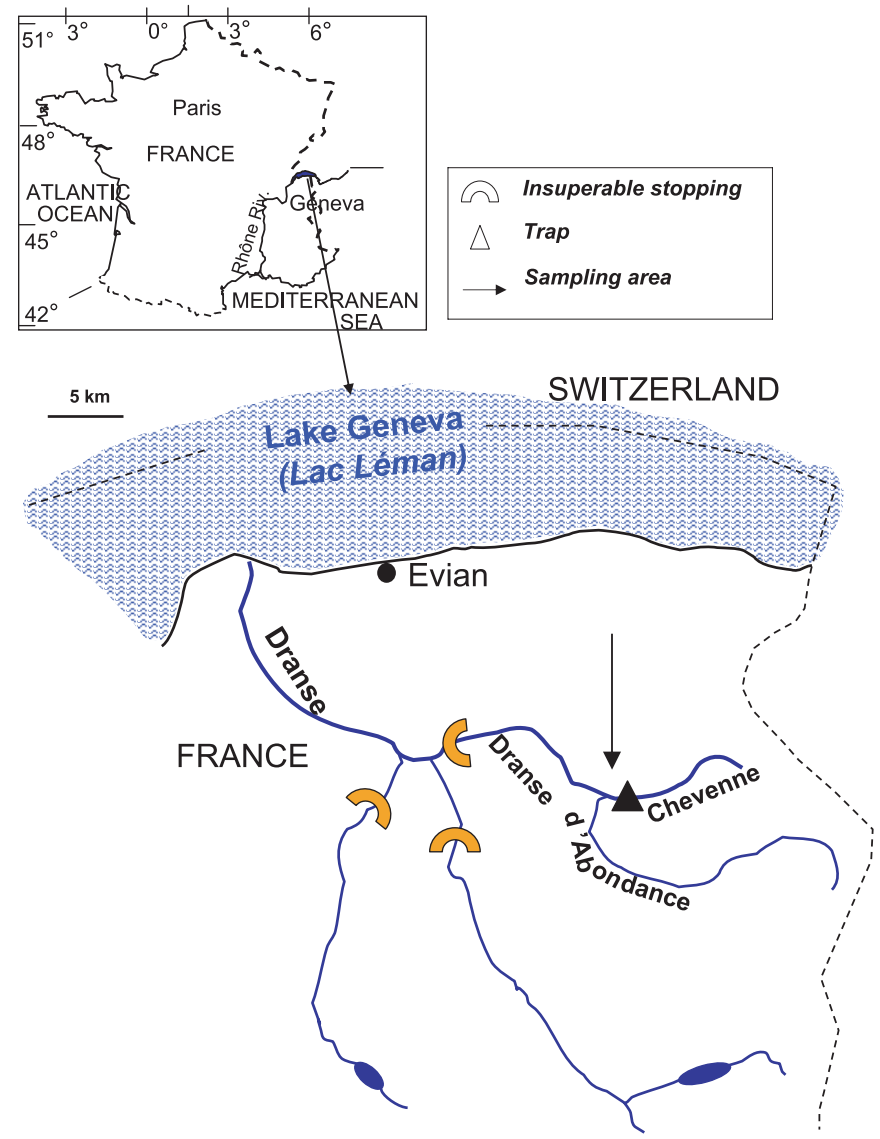

Fig. 1. Watershed map of Lake Geneva (Lac Léman) and trout sampling location.

Table 1. Distribution of the samples according to genotype and sampling site (Dranse River or Chevenne Brook) in September 1995.

\begin{tabular}{lcc}
\hline Genotype & Chevenne Brook & Dranse River \\
\hline Atlantic trout & 50 & 14 \\
Mediterranean trout & 130 & 36 \\
Hybrid & 10 & 24 \\
\hline
\end{tabular}

and, once they had ovulated, by the fact that a few eggs were expelled in response to slight abdominal pressure. The spawning trout sampled in the trap were of the Mediterranean lineage (Largiader, unpublished data). The sample consisted of 42 male spawners and 57 female spawners.

\subsection{Landmark points}

The shape of each specimen was captured by recording the coordinates of 14 morphological landmarks (Fig. 2). Landmark 3 represents the end of the head and is not perfectly homologous among specimens, but we do not see better landmark in that portion of the body. To limit the inaccuracy of this point, its position was marked by the vertical projection of the landmark 13 (visually with the computer's mouse). Distances were recorded from digital images obtained by scanning the slides prepared. The digital images were processed using image processing program developed using Optima 6.5 


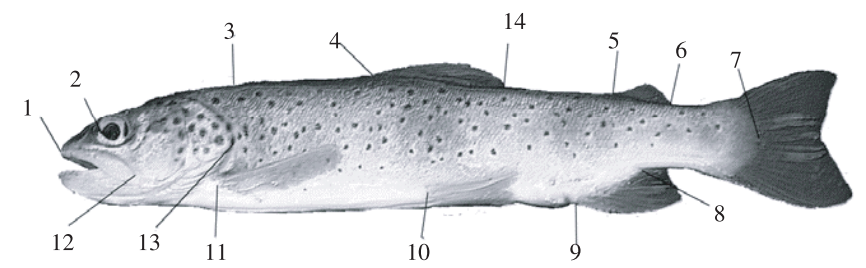

Fig. 2. The 14 landmark points used for the geometric morphometric analysis. 1, snout extremity; 2 , front eye limit; 3 , end of head, indicated by the vertical projection of point $13 ; 4$, front insertion point of the dorsal fin; 5, front insertion point of the adipose fin; 6 , rear contact point between the adipose fin and the back; 7, rear extremity of the lateral line; 9 , forward insertion of the anal fin; 10, forward insertion point of the ventral fin; 11, forward insertion point of the pectoral fin; 12, rear extremity of the upper jaw; 13, Vertical tangent to the operculum; 14, rear contact point of dorsal fin with the back.

software. The program involved placing the landmarks originally defined on each image. The software then calculated the coordinates of the landmarks automatically. The morphology of the fish was investigated in a two-dimensional space. The $x$ and $y$ coordinates were therefore determined for each of the specified points.

\subsection{Analytical process}

\section{Transformation of the data}

The characteristic conformations of the male and female individuals were determined and compared using the TPS (thin-plate spline) method, discussed in detail by Bookstein (1991). The original $x$ and $y$ coordinates of the 14 landmarks were fed into the tpsRelw program (c) F. James Rohlf 2003). This software subjects the data to a general procrustes analysis (GPA), which superimposes the conformations in order to eliminate any morphological variations introduced as a result of differences in the position, orientation or size of the specimens. This superimposition was achieved by orthogonal projection onto a plane tangential to the conformation space of the corresponding point in the consensual individual (Dryden and Mardia 1999). This last step converted the conformation curve Riemann space into Euclidean space, thus making it possible to carry out the conventional calculations of multivariate linear statistics. After this superimposition, the software breaks down the morphological difference into a series of nonuniform components, described as partial warps. The scores of the specimens on the partial warp axes constituted the shape variables that were used in the subsequent statistical analyses (Rohlf 1999).

\section{Multivariate statistical analyses}

The tpsRelw software makes it possible to introduce shape variables into a Principal Component Analysis (PCA), and to visualize the warping associated with the various principal components (PCs). These components are described as relative warps in the context of a TPS approach (Bookstein 1991). PCAs can detect any regularity within the sample. In a morphometric analysis, these regularities correspond to simultaneous displacements of anatomical points that are often observed in the specimens. A value is assigned to each relative warp. This is known as the specific value, and is expressed as a percentage, reflecting the proportion of the variation accounted for by this component. PCA automatically classifies the relative warps in decreasing order of their specific values. The greatest variations, generally attributable to biological factors, occur in the first few components. In contrast, the individual variations classified as background "noise" are relegated to the components lower down the list. The interpretation is therefore usually limited to the first few relative warps. The morphological warps associated with each component are visualized by observing the conformations corresponding to the points located at the ends of the axes. The changes in shape are illustrated by a potentially warpable grid, which represents the warps relative to a consensus (an average individual). The factors responsible for the dimorphisms are identified by looking for any features that distinguish between the groups falling on either side of the axis.

In a second part, the scores of the specimens on the relative warp axes, were exported into the S-plus 6.1 program (C) Insightful Corp 2002) and subjected to discriminant functions analysis (DFA).

\section{Sexual dimorphism at the spawning stage}

The objective was to find out whether morphological characteristics can be used to identify the sex of trout. Before interpreting the discriminating functions, we tried to check whether any of the morphological differences observed between the males and females were statistically significant. To do this, we used Hotelling's $\mathrm{T}^{2}$ test to test the equality of the means in two multivariate groups. We should note that this test is simply the multivariate version of Student's $t$-test applied to comparing two groups of individuals. The percentage concordance between the true sexual classification and that based on the morphotype was assessed by cross validation. This method provided a better way of estimating the error rates when the initial sample was too small to allow us to extract a sufficiently large validation sample. The principle is to eliminate one individual, and to calculate the predictive model from other observations. This model is then used to predict the sex of the individual withdrawn. The operation is repeated for each individual, and the proportion of correct and incorrect classifications are deduced.

\section{Variations in body shape within the resident population}

One of our objectives was to find out whether morphological attributes could be used to identify the genotype of the trout. Before interpreting the discriminating functions, a multivariate analysis of variance (MANOVA) was carried out to see whether any morphological differences detected between the strains of trout were statistically significant. The MANOVA method is not based on a single multivariate statistical test, but draws on four such tests: the Pillai-Bartlett, Wilk, HotellingLawley and Roy tests. These four multivariate tests usually yield similar results. However, in certain situations, their conclusions may diverge, and most authors agree that in such circumstances the Pillai test is the most powerful and the most 


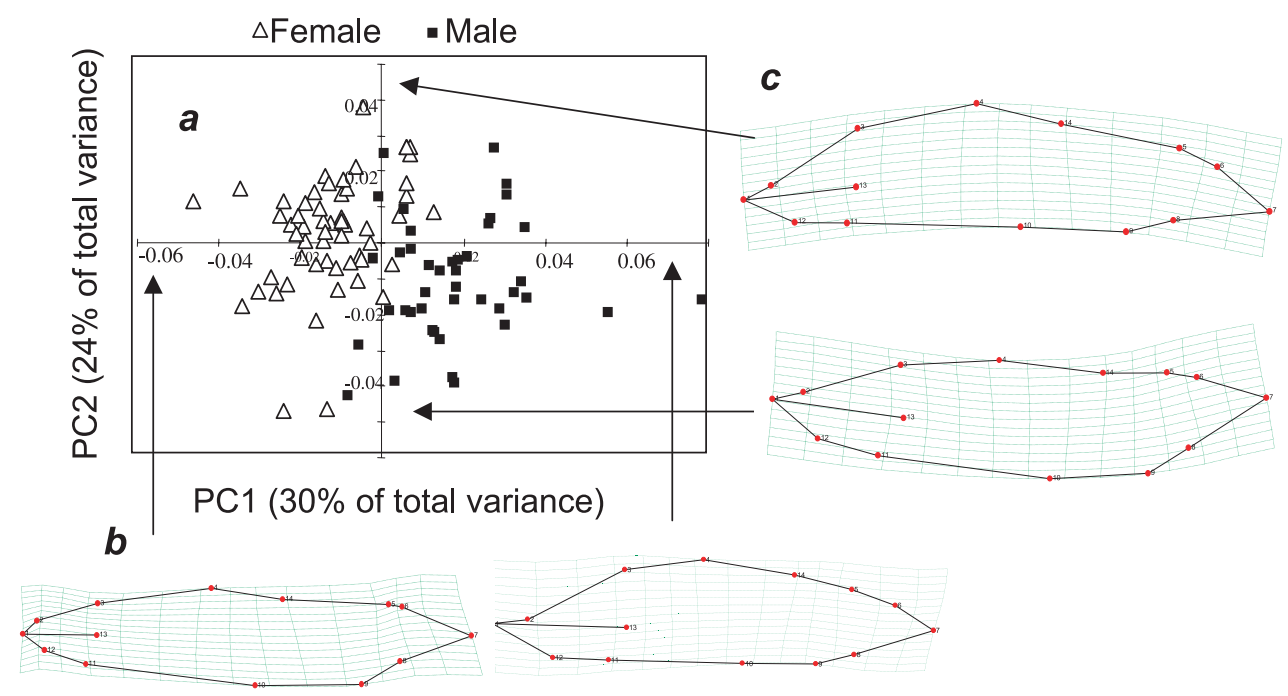

Fig. 3. (a) Projection onto the first (PC1) and second (PC2) principal components of the 99 sexed spawning trout, (b) extreme warps associated with the first principal component (PC1), which distinguishes between male and female spawners during the breeding season. (c) Extreme warps associated with the second principal component.

robust. The MANOVA determines to what extent the vectors of the means between genotype groups can be considered to be the same. However, it does not indicate whether any differences observed are attributable to a particular group. As for the spawners, a Hotelling $\mathrm{T}^{2}$ test intended to carry out a pairwise comparison of the genotype groups was used in addition to the MANOVA data.

\section{Results}

\subsection{Sexual dimorphism during the spawning season}

The first component of the model illustrates the differences in body shape that are linked to the sex of the trout. This accounts for $30 \%$ of the body-shape variation found in the sample (Fig. 3). The observation of the extreme warps associated with the two sexes revealed several similarities and differences between the males and females. The dorsal part (landmarks 3, 4 and 14) was clearly more protuberant in the males, and this gave them greater body height. The space occupied by the head relative to the whole body was definitely greater in the males. This is reflected in a larger head and upper jaw. This difference directly affects the distance between the tip of the head (landmark 3) and the forward insertion of the dorsal fin (landmark 4), which is naturally shorter in males. The shift in position of the eyes (landmark 2) seems to be also an important aspect of sexual dimorphism, unless this observed difference comes in fact from the position of landmark 1 with a mouth more advanced for the male. The size of the fins also depends on the sex of the trout. The main dimorphisms concerned the dorsal fin, which was smaller in the female specimens, and as a result, this fin was further away from the adipose fin in females than in males. The adipose fin was also smaller in females, which in turn meant that it was further from the caudal fin. The point of insertion of the pectoral fin (landmark 11) was further back in the males, which brought it nearer to the
Table 2. Concordance between the true classification of the sex of the fish (during spawning) and the sexual classification based on morphometric geometric analysis.

\begin{tabular}{ccccc}
\hline & \multirow{2}{*}{ Number } & \multirow{2}{*}{ Classification error } & \multicolumn{2}{c}{$\%$ assigned to group } \\
& & & Males & Females \\
\hline Males & 57 & $3 \%$ & $97 \%(55)$ & $3 \%(2)$ \\
Females & 42 & $10 \%$ & $10 \%(4)$ & $90 \%(38)$ \\
Total & 99 & $6 \%$ & & \\
\hline
\end{tabular}

insertion of the ventral fin. The upper jaw (segment 1-13) was markedly larger in the males than females (Fig. 3).

Morphometric geometrics give us a lot of way to explore more precisely our data. It could be interesting to make a study compared of the observations with multivariate analysis of truss distances.

The existence of sexual dimorphism was confirmed statistically by the discriminant functions analysis. The morphological differences between males and females were classified as highly significant $(F=16.60, p<0.0001)$. The graphical representation of the specimens on the discriminating axis also confirmed this clear distinction between males and females, and provided a visual representation of the quality of discrimination (not illustrated). The concordance between the classification based on the morphotype and the true classification confirms the discriminating power of the sex factor (Table 2). The morphological attributes yielded a correct diagnosis in $97 \%$ of the males and $90 \%$ of the females. The global error rate, without any distinction of the sexual characteristics, was $6 \%$.

The less important warps are included in the second component of the model (PC2). This accounts for $24 \%$ of the total variance (Fig. 3). The warping associated with this component illustrates a global change in body shape that is reflected by an increase in the general body curvature of the trout. It should be noted that this curvature occurred in both sexes and was therefore detected even if only male or female specimens were taken into account. 
Investigating the relationships between the size and the component scores of the specimens made it possible to show that the body size and curvature of these trout were linearly related. This dependence between the size and body conformation was only found for the second component, with which the body curvature is associated (Fig. 4b). The first component, which it should be remembered reflects the sex-linked warps, is clearly independent of size (Fig. 4a). This independence of size was also confirmed for the other components; although we have not included them all here to avoid excessive to avoid excessive detail. The general curvature of the body is therefore an allometric warp. More specially, the trout become more concave in shape as they grow) We lengthily questioned about this deformation, thinking that it could be an artefact of image processing. This hypothesis cannot be completely excluded. The individuals of big size would have a risk more important to be curved what would explain the relation of dependence between the size of trout and their curve. However, we don't think that this assumption maybe exact. We cannot exclude an effect of evolution of the ratio dorsal/ventral musculature or backbone curvature with age. We observed a concave curve for the individuals of big size and a convex curve for the individuals of small sizes (Fig. 4c). We think that a curve related to a bad positioning of fish at the time of the capture of the data would result rather in a uniform distribution of the concave and convex curves, independently of the size of the specimens. All trout were treated in the same manner: caught alive, anesthetised and then immediately photographed. That means that the image acquisition was standardized and the same for large and small trout, it is not an artefact due to a rigor mortis effect, and that it is not an effect of conservation process like freezing. Moreover landmarks were taken in the sagital plane and not in frontal or transversal planes more submitted to size variations of the trout.

\subsection{Morphological variations amongst the resident population}

\section{Main source of morphological variation: body curvature}

The first component of the model accounts for $21 \%$ of the morphological variation. The warping associated with this illustrates a global change in conformation, leading to general curvature of the bodies of the trout (Fig. 5). This curvature does not correspond to any genotypic or geographic dimorphism. In fact it is also found if the specimens compared all belong to a single genotype or come from the same geographical habitat: the Dranse River or the Chevenne Brook. We do not have any information about the sex of these fish, but it is unlikely to be a criterion that differentiates between males and females. Similar curvature was indeed observed in the batch of sexed mature spawners collected two-to-three months later (see previous paragraph), and in which it was shown that body curvature was not a sexual characteristic. In contrast, in this sample of spawners we found that the size of the trout was related to their body curvature, suggesting that this warp is an allometric phenomenon. A multivariate regression of the size on the score of the individuals on the relative warp axes confirmed that the data obtained during the spawning season were
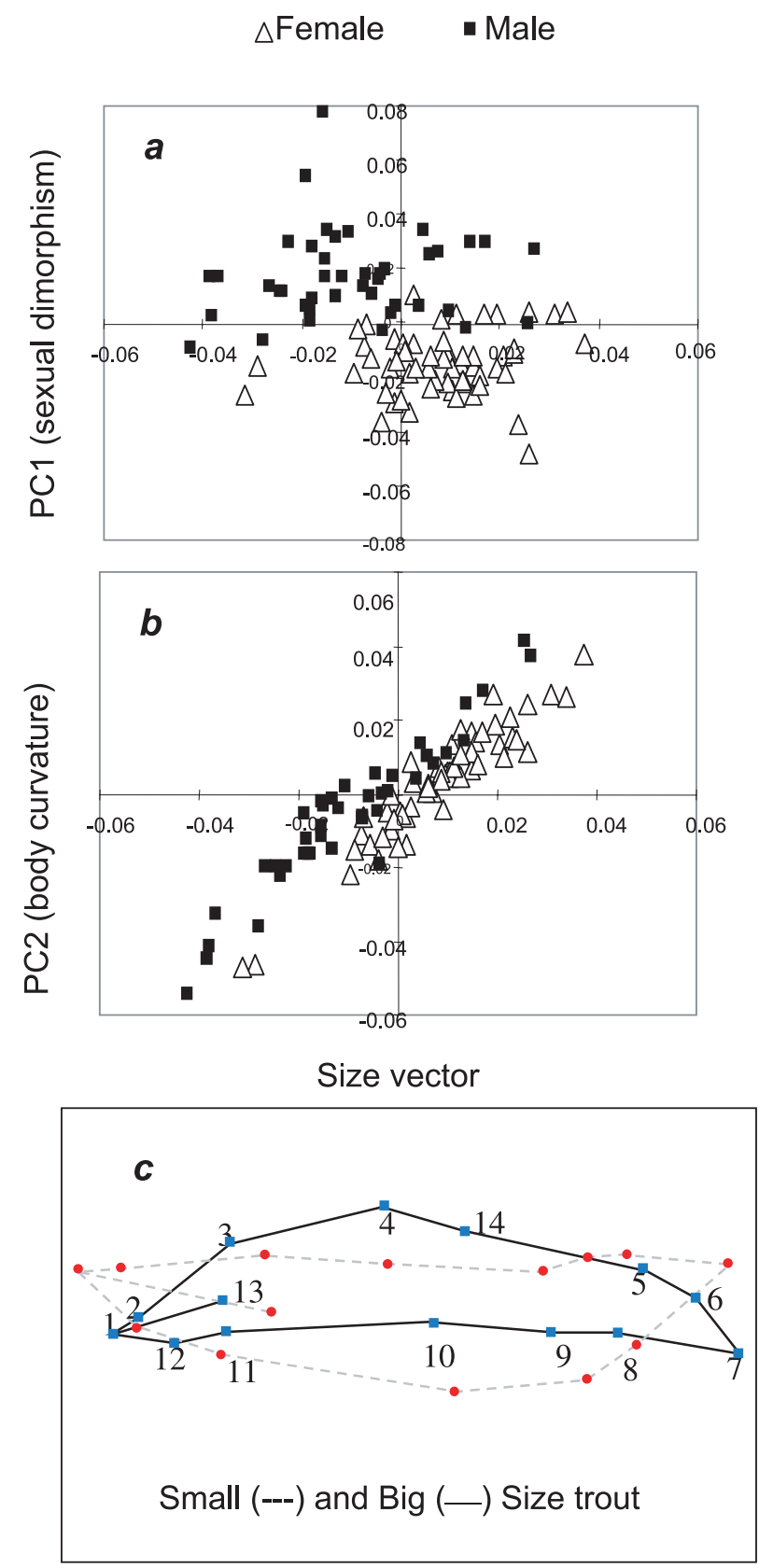

Fig. 4. Relationship between the size vector and the scores of the male and female trout, on the first (a) and second (b) principal components. (c) Superimposed deformations extreme with PC2 and which opposes the individuals of small size (- - -) and big size (-). The growth of trout results in a concave curve of the body.

also valid outside the breeding season. The regression model was classified as being significant to the $5 \%$ threshold (Fisher test, $F=15.26, p<0.0001)$. This means that part of the morphological variation is allometric. In addition, a linear relationship was found between the size of the trout and the first relative warp with which body curvature is associated (Fig. 6a). The general curvature of the bodies of the trout therefore depends on their size. The curvature is convex in small fish, and becomes concave in the larger ones. The 2 nd and 3 rd relative warps are apparently unrelated to size (Figs. 6b,c). This lack of 
- Indigenous trout (Mediterranean)

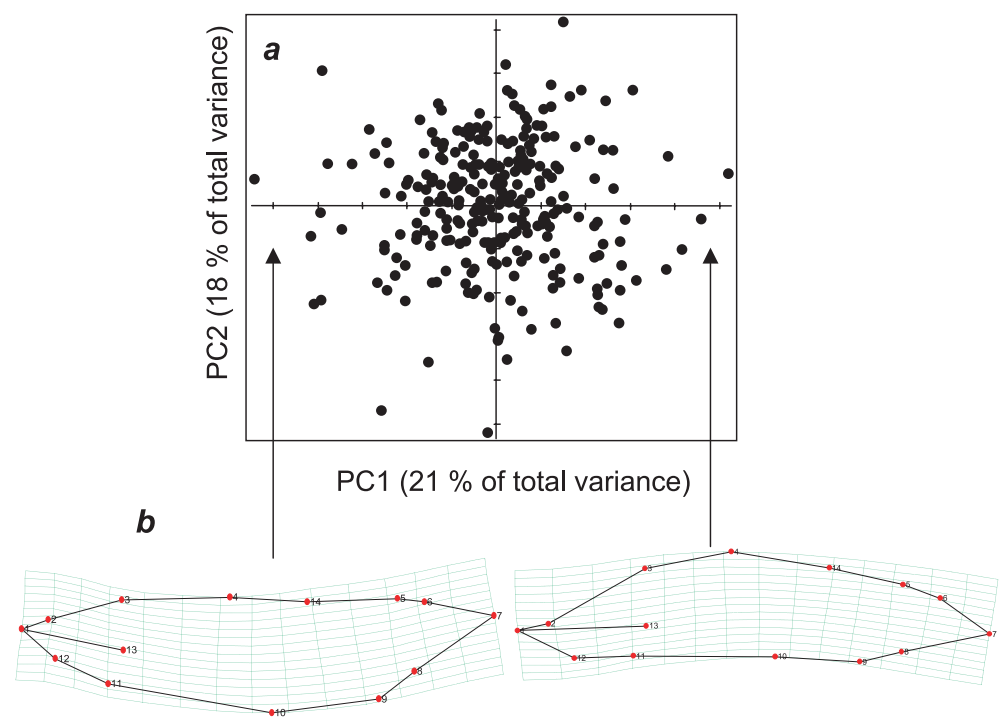

Fig. 5. (a) Projection onto the first (PC1) and second (PC2) principal components of trout from the resident population in September. (b) Extreme warps associated with first principal component, which distinguishes between small and large sized trout.

relationship was also confirmed for the higher-ranking components, but for the sake of simplicity we have not included this data here.

\section{2nd source of morphological variation: sexual dimorphism}

The dimorphisms of lesser importance are visualized in the second component and account for $18 \%$ of the total morphological variation. These dimorphisms are not related to genotypic or geographical differences, since no obvious contrast is observable on the second component. However, the analysis of the warps associated with this component reveals numerous common points with the sexual dimorphism observed in the sample sampled during spawning. This observation suggests that the differences in body shape associated with the second component are attributable to the sex of the specimens.

\section{3rd source of morphological variation: genotype dimorphism}

Discrimination between the genotype groups is based on the third relative warp, which accounts for $13 \%$ of the total variability (Fig. 6c). Genotype therefore constitutes the third largest source of morphological variation in trout. The four statistical tests used to compare the mean values indicated that the morphological differences between the genotype groups were highly significant (Table 3 ). This finding suggests a lack of homogeneity in conformation between the different strains of trout. Furthermore, Hotelling's $\mathrm{T}^{2}$ test showed that the morphological differences between the pairs of genotype groups were all significant. However, it should be noted that the value of $F$ associated with the comparison of the Mediterranean and hybrid trout $(F=2.74, p=0.00062)$ was clearly lower than that found between the Mediterranean and Atlantic strains $(F=24.09, p<0.00001)$ or between the Atlantic and hybrid trout $(F=11.36, p<0.00001)$. The morphological differences between the hybrid trout and the Mediterranean trout
Table 3. Influence of genotype on trout morphology. Comparison of the mean coordinates among the various trout genotypes.

\begin{tabular}{llrlll}
\hline Statistical Test & Statistics & F-ratio & df & df2 & $p$ \\
\hline Wilks Lambda & 0.3449 & 11.572 & 30 & 494 & $<0.0001$ \\
Pillai Trace & 0.7385 & 9.678 & 30 & 496 & $<0.0001$ \\
Hotelling-Lawley & 1.6576 & 13.592 & 30 & 492 & $<0.0001$ \\
Trace & & & & & \\
Roy Greatest Root & 1.4960 & 24.734 & 15 & 248 & $<0.0001$ \\
\hline
\end{tabular}

therefore seem to be less marked than those between the hybrid and Atlantic trout.

The graphical representation of the specimens on the discriminating axes confirms the results of the statistical tests, and makes it possible to visualize the quality of the discrimination (Fig. 7). Most of the information is represented on the first discriminating axis, which accounts for $90 \%$ of the total variability. This distinguishes the Atlantic trout from the Mediterranean and hybrid trout. The second discriminating axis accounts for $10 \%$ of the total variability. It distinguishes between Mediterranean and hybrid trout. Most of the morphological variation attributable to the genotype was therefore attributable to differences between the Atlantic and Mediterranean specimens. Representing individuals on discriminating axes makes it possible to confirm the findings of the Hotelling $\mathrm{T}^{2}$ test. The distinction between the Atlantic trout and the other two genotypes was particularly striking. The distinction between the hybrid and Mediterranean trout was less obvious, to the extent that a high proportion of hybrid individuals were indistinguishable from Mediterranean individuals. Nevertheless, the distinction between the fish lying either side of the discriminating axes is real, and reflects the morphological differences between these two genotype groups. This is why the statistical tests found that the differences between the hybrid and Mediterranean trout were significant. The problem is that the morphological attributes that distinguish between 

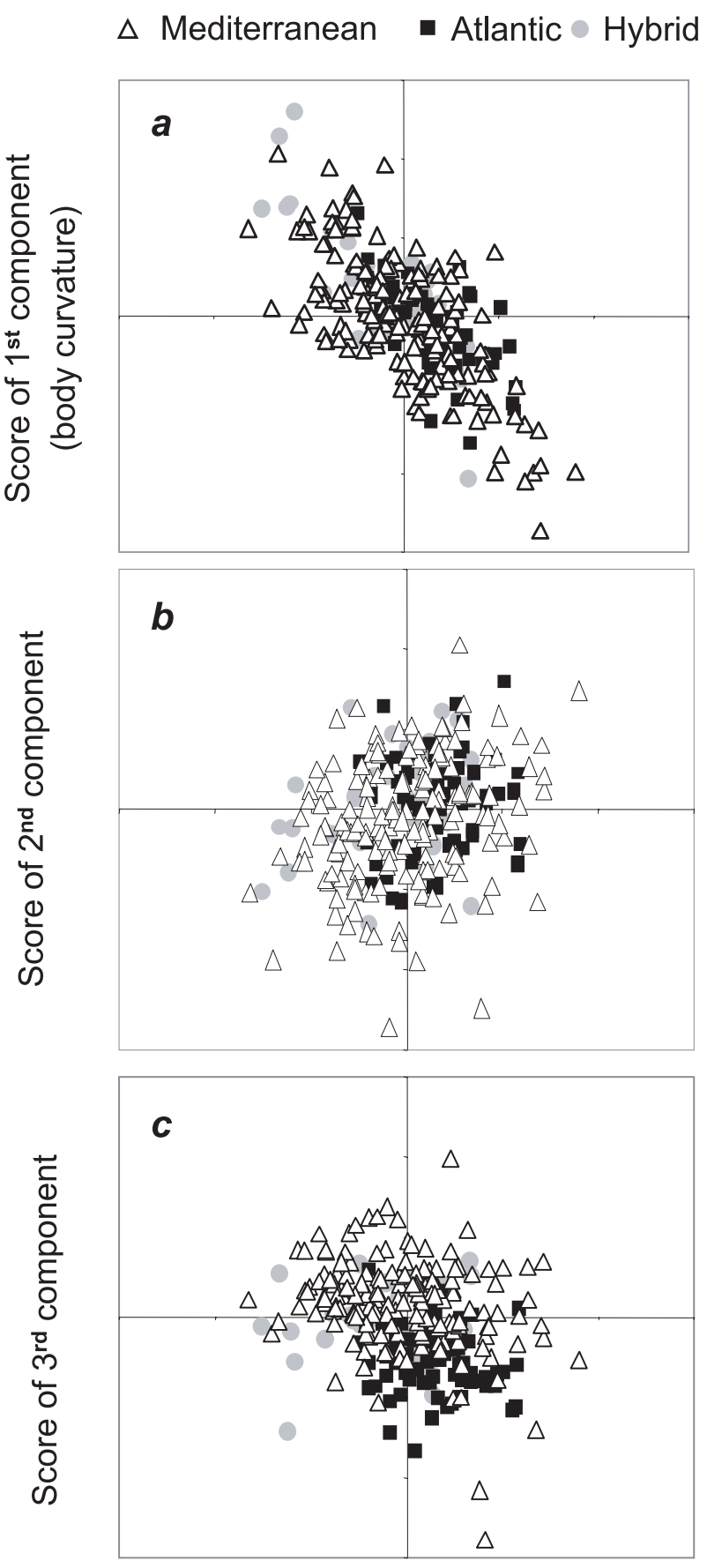

Size vector

Fig. 6. Relationship between the size vector and the score of the Atlantic and Mediterranean lineages and the hybrids on the first (a), second (b) and third (c) principal components.

the hybrid trout and the Mediterranean specimens were either not sufficiently marked, or else were not confirmed in a sufficient number of trout. Whatever the reality, the reliability of the morphological attributes used is not sufficient to identify the hybrid trout properly.

The concordance between the classification based on the morphotype and that based on the genotype also confirms
$\Delta$ Mediterranean $\quad$ Atlantic $\bullet$ Hybrid

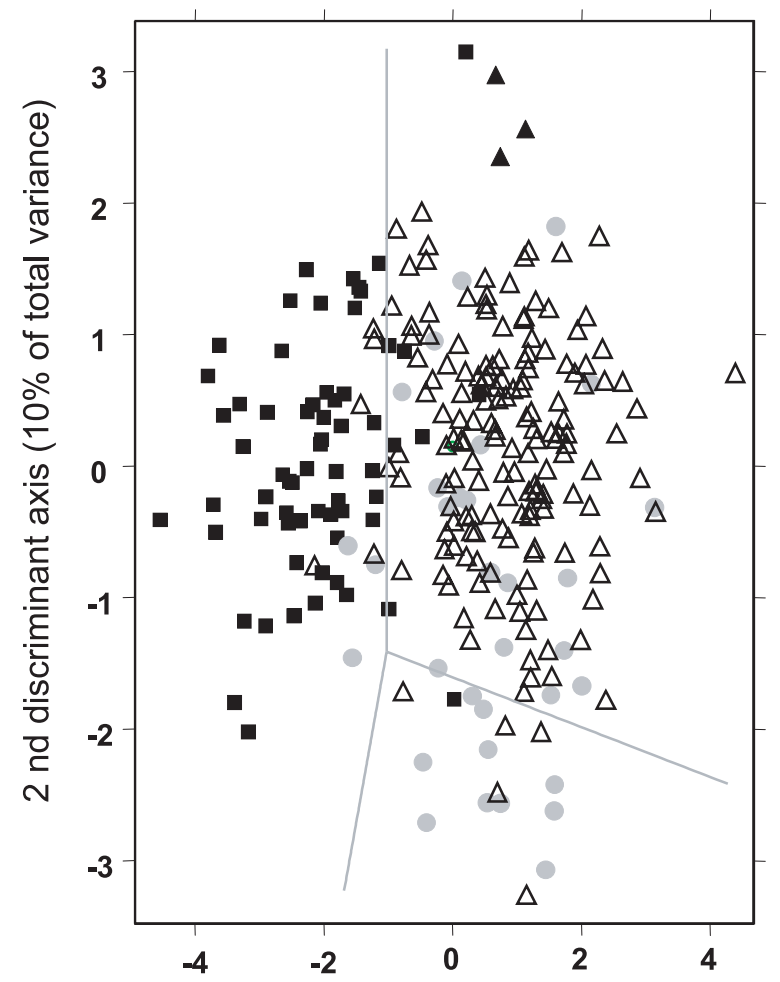

1st discriminant axis ( $90 \%$ of total variance)

Fig. 7. Scores of Atlantic lineage, Mediterranean lineage and hybrids on the discriminant axes.

these results (Table 4). It appears that the morphological attributes provide a correct genotype diagnosis in $86 \%$ (55 out of 64) of the Atlantic specimens, and 91\% (151 out of 166) of the Mediterranean specimens. In contrast, the morphological characteristics are unreliable indicators of genotype in hybrid trout. The predictions of hybrid trout result in an error rate of $76 \%$ (26 out of 34). Most of the genotype predictions carried out on hybrid trout classified them are being Mediterranean (23 out of 34 ). To conclude, we can suggest that the morphological characteristics do provide a relatively reliable recognition of the parental strains (Atlantic and Mediterranean), but perform badly in identifying hybrid trout, which are generally confused with Mediterranean specimens.

The observation of the extreme warps associated with the third component reveals various points of similarity and differentiation between the Atlantic and Mediterranean trout. The Mediterranean trout is more elongated than the Atlantic trout (Fig. 8). The part of the body located between the tip of the head (point 3) and the rear contact point of the dorsal fin with the body (point 14) appears to be more protuberant in the Atlantic strain. The same is true of the points located on the ventral part of the body (points 9 and 10). The dorsal fin (distance between points 4 and 14) is bigger in the Mediterranean trout (Fig. 8). Another important differentiated zone is the position of the snout. This seems to be held higher in the Mediterranean trout, whereas it points downwards in the Atlantic trout. In contrast, the other landmarks that define the 
Table 4. Concordance between classifications based on genotype and those based on morphotype.

\begin{tabular}{|c|c|c|c|c|c|}
\hline & \multirow{2}{*}{ Number } & \multirow{2}{*}{$\begin{array}{c}\text { Classification } \\
\text { error }\end{array}$} & \multicolumn{3}{|c|}{$\%$ assigned to group } \\
\hline & & & Atlantic & Hybrid & Mediterranean \\
\hline Atlantic & 64 & $15 \%$ & $85 \%(55)$ & $2 \%(1)$ & $13 \%(8)$ \\
\hline Hybrid & 34 & $77 \%$ & $9 \%(3)$ & $23 \%(8)$ & $68 \%(23)$ \\
\hline Mediterranean & 166 & $9 \%$ & $5 \%(9)$ & $4 \%(6)$ & $91 \%(151)$ \\
\hline Combined & 264 & $19 \%$ & & & \\
\hline
\end{tabular}

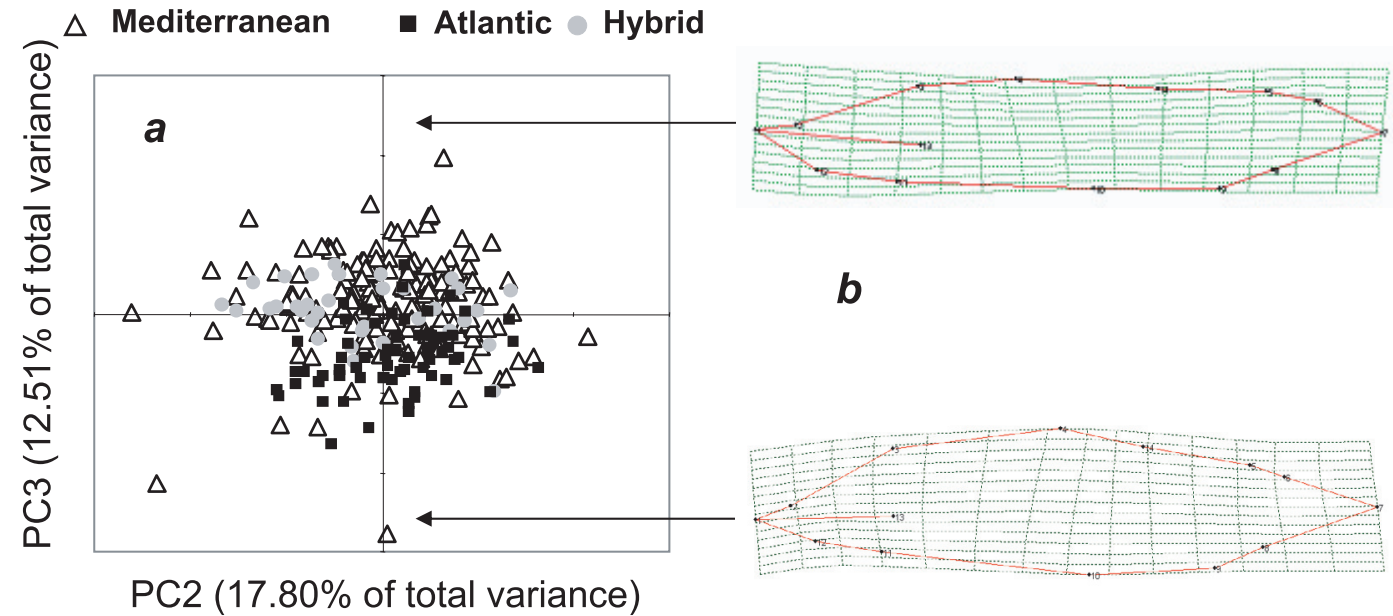

Fig. 8. (a) Projection onto the second (PC2) and third (PC3) principal components of trout of the sampled in the resident population in September. (b) Extreme warps associated with the third (PC3) principal component, which distinguishes between the Atlantic and Mediterranean lineages and the hybrid trout.

outline of the fish are very similar. This is true of point 12 on the head, of the forward insertion of the pectoral fin (point 11), and finally points 5,7 and 8 , located beside the caudal fin.

\section{Discussion}

Morphological plasticity is common in the salmonids (Martin 1949; Currents et al. 1989; Beacham 1988), and in the brown trout (Salmo trutta) in particular (Lascaux 1996). According to Fleming et al. (1994), the phenotype malleability of the salmon during ontogenesis allows this fish to adapt itself to the local environment. Taylor (1991) defines local adaptation as a process by which, within a population, natural selection increases the frequency of the characteristics that improve the survival and/or reproductive success of the individuals that have them.

Using geometric morphometrics, the present study has identified several body shape variations in trout in their natural habitat.

\subsection{Sexual dimorphism}

The main sexual dimorphism between spawning males and females of wild trout of the Mediterranean genotype detected in the present study using geometric morphometrics study was the fact that the dorsal part of the body was higher and more protuberant in the males, which also had bigger heads. We also found that the dorsal and adipose fins were bigger in males than females.

These findings parallel those of other studies (Beacham 1984; Reyes-Gavillan et al. 1997) using conventional morphometrics. Reyes-Gavillan et al. (1997) studied the body shape of the sedentary brown trout of Northern Spain. Immature trout were found to be monomorphic, but sexual dimorphism appeared in the adults. The males acquired a bigger head, and the females had a larger abdomen. According to these authors, sexual selection probably promotes the larger head size in the males, and fertility selection the relatively larger abdomen in the females. According to the work of Beacham (1984), in the chum salmon (Oncorhynchus keta), the males also have a larger head, a thicker caudal peduncle and a bigger dorsal fin than the females.

Ethological studies (Swain and Holtby 1989; Holtby et al. 1993) in the coho salmon (Oncorhynchus kisutch) suggest that there is a link between body shape and the success of aggressive interactions between coho salmon (Oncorhynchus kisutch). According to Quinn and Foote (1994), in the salmonids, the dominant male fertilizes more eggs. Exaggerated development of the jaws enhances the effectiveness of aggressive behavior. In a situation of competition between breeding males, having larger structures for use in fighting behavior (jaw, head, and teeth) confers an advantage (Flemming and Gross 1994; Quinn and Foot 1989). One ethological study (Peterson et al. 1999) has shown that females preferentially selected the potential mate with the biggest adipose fin. 
Out-Period of Reproduction
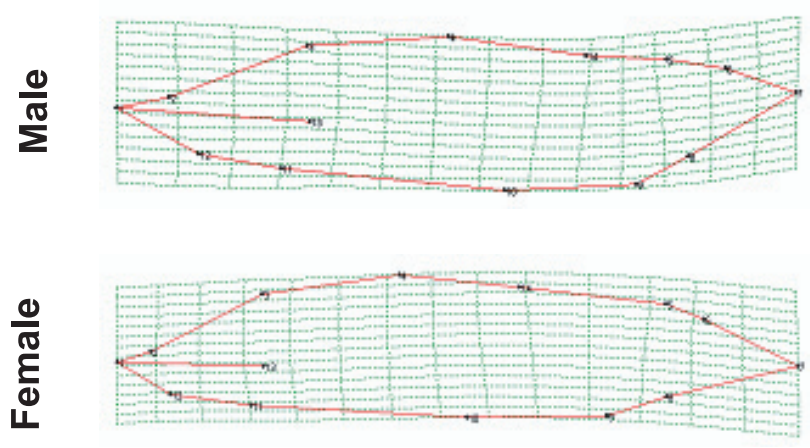

During Reproduction Period
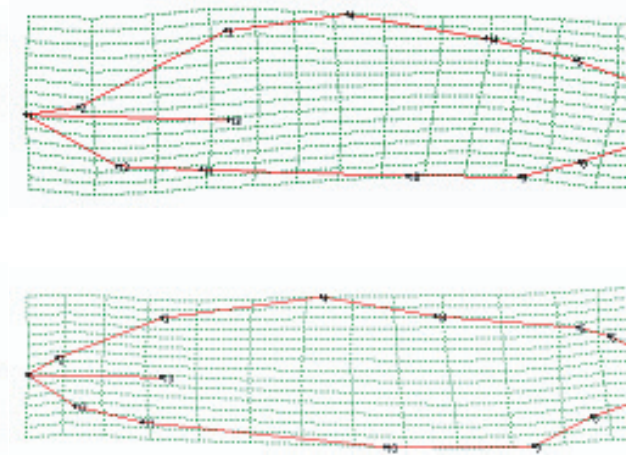

Fig. 9. Sexual dimorphism is more marked during the breeding season, in particular in the male trout with a protuberant dorsal part.

In the present study, the sample investigated outside the breeding season was examined at the end of September i.e. about two months before the spawners were sampled during the breeding season. In the September sample, the sex of the trout constituted the second greatest source of morphological variation. It became the most influential factor during spawning. Sexual dimorphism therefore seems to be more marked in the sample of spawners during the breeding season and, in particular, in the males the dorsal part of the body becomes more protuberant and more curved (Fig. 9). These findings concur with the data reported by Davidson (1935), Tchernavin (1938) and Vladykov (1962), showing that adult salmonids can undergo morphological changes during the spawning season, and that these affect the head and trunk particularly.

We cannot rule out the possibility that the September sample could have included some immature trout. Any such juveniles would have tended to dilute the impact of sexual dimorphism. In the coho salmon (O. kisutch), Fleming et al. (1994) have reported that the morphology of immature parrs did not depend on their sex, whereas the morphology of mature male parrs did differ from that of both immature males and female parrs. The mature males had a longer and higher head, longer pectoral fins, and a higher body and caudal peduncle.

\subsection{Variations in body shape that are unrelated to sex}

This novel contribution made by geometric morphometrics has shown that the body shape becomes more concave as the trout get bigger. The study also identified differences in shape between the Atlantic trout and the Mediterranean or hybrid trout: the Mediterranean trout were more elongated, had a larger dorsal fin and their heads pointed higher up.

This raises the question of the explanation and/or biological, ecological and evolutionary significance of these changes in the body shape of trout. Several studies (Ridell and Legett 1981; Taylor and McPhail 1985) have demonstrated that morphological differences exist that are linked to genetic differences between different populations of a given species. According to Riddel and Legett (1981), in populations of fish, the genetic sources of variations in phenotype are generally viewed as being less influential than environmental differences in determining the inter-population phenotype differences. We cannot rule out the possibility that variations in body shape related to size and genotype may in fact be linked to differences in habitat (water flow in particular), to different exploitation of trophic resources or to whether the fish have been farmed or not.

As far as we are aware, the literature does not contain any previous reports in the natural habitat, of the existence of body curvature linked to an increase in size. However, this characteristic of concave curvature for old fish is "visually" observed on the field (wild fish and in the hatchery). Moreover, studies of farmed trout (Bonnet, personal com.) have indicated that this type of curvature may be linked to the fact that the dorsal musculature develops to a greater extent than the ventral musculature. In an unpublished work concerning rainbow trout, Bonnet clearly showed a link between convex and concave appearance and the differential development of trout musculature (concave trout have a dorsal musculature more developed than ventral musculature, convex trout have a ventral musculature more developed than the dorsal musculature). In the natural habitat, as the trout grows, it colonizes a larger territory, uses a bigger shelter and is capable of moving into habitats with faster flowing water, which gives it access to greater trophic resources. It is therefore possible that changes in body shape, which may be linked to changes in musculature, may accompany these changes in habitat as the trout grows.

Several studies (Riddel and Legett 1981; Mc Laughlin and Grant 1994; Imre et al. 2002) have shown that in the salmonids, morphological differences exist between individuals living in habitats with a strong current and those living in habitats with less water flow. In zones with very high water flow, the fins tend to be bigger and the body narrower. According to Imre et al. (2002), this is a consequence of the plasticity of the phenotype in response to the hydraulic conditions. Valentin et al. (2002) point out that a narrower body reduces the energy cost of swimming by improving the hydrodynamics.

Data obtained in Arctic char (Salvelinus alpinus) in Icelandic lakes by Gilason et al. (1999) indicate that the trophic adaptation may act as a driving force in segregating the different body shapes. According to (Skulasson et al. 1999), in some cases, the morphological differences are induced by the environment, whereas in others, the differences in phenotype reflect genetic differences. Phenotype segregations based on the availability of resources are positively correlated to the degree 
of reproductive isolation. Morphometric analyses (Gardner et al. 1988) have shown that the Arctic charr in Loch Rannoch in Scotland are dimorphic. Benthic Arctic charr have longer heads, bigger eyes and more powerful jaws than the pelagic Arctic charr. Various data (genetic analyses and reproductive isolation) suggest that these morphs did not originate from the same gene pool.

Restocking of the zone being investigated has been taking place for about one hundred years, using farmed strains produced from Atlantic individuals. When Mediterranean trout were found in this zone (as in the samples we investigated), these were wild, native trout. In this study, the differences in body shape observed between the Atlantic and Mediterranean genotypes could therefore also correspond to a difference between the wild native population, in the case of the Mediterranean form, and the population introduced as a result of restocking, in the case of the Atlantic strain. Indeed, according to Fleming et al. (1994), farming exposes the fish to new developmental and evolutionary pressures that can sometimes lead to rapid changes in their phenotype. In salmon, for instance, according to Fleming et al. (1994), the shape of the farmed individuals has usually diverged from that of the wild individuals, and they generally have smaller fins and head, and a narrower caudal peduncle. In salmon, body shape is determined by both genetics (Riddell et al. 1981; Taylor and McPhail 1985; Gjerde and Scaeffer 1989; Beacham 1988) and the habitat (Martin 1949; Winans 1984; Currens et al. 1989). Fleming and Gross (1989) suggest that changes in body size and height, in the length of the front of the head may be evolutionary responses that have been selected during farming. They also suggest that this selection may also account for the differences in the shape of the fins.

In the rivers investigated in this study, the Mediterranean and hybrid trout grew more slowly than the Atlantic trout. This characteristic could account for some of the inter-genotype morphological differences. According to Martin (1949) and to Ihssen et al. (1981), the relative sizes of some parts of the body are influenced by the growth rate. The populations with a low growth rate typically have some body parts that are in fact proportionally larger than those of populations with higher growth rates.

\section{Implications for fish management}

The present study suggests that it would be possible to use geometric morphometrics to help fish stock managers to trace native populations throughout huge hydrographic systems, i.e. to identify a Mediterranean component (or Mediterranean or hybrid as in this study). This can subsequently be confirmed by genetic analyses that focus on the populations in which a Mediterranean component has been detected by the morphometric analysis. Genetic analyses could then be used to identify the Mediterranean populations that have undergone the least introgression. The high cost and small number of laboratories able to carry out genetic analysis of fish mean that the application of genetic analysis is still limited to small samples, and so it is important to be able to select the best populations to test. This new tool can therefore take its place alongside that of traditional morphology (Lascaux 1996) for use in studying and managing fish stocks on the basis of lineages and populations.
Pictures taken in fish ladders fitted with recording cameras could be analyzed using geometric morphometrics in order to determine the sex of the spawning migrant trout without having to handle the fish themselves.

\section{Conclusion and further developments}

This exploratory study has demonstrated those body shapes differences exist that are related to the sex, size and genotype of the fish. These data, combined with data from the literature, suggest interpretations in terms of adaptation of breeding behavior to habitat and trophic resources. Geometric morphometrics therefore looks as though it could be a useful tool for investigating these mechanisms. The visual inspection of extreme warps can lead focusing on particular zones, using truss analysis to obtain quantitative deformations. Understanding body shape could help to elucidate some of the mechanisms involved in pairing during breeding (reproductive ecoethology) and adapting to the habitat, and also help us to understand and predict some of the impacts of restocking on wild populations of salmonids.

The data acquired about sexual dimorphism lead us to recommend that in future more detailed studies of trout morphology should, whenever possible, include information about the sex and sexual maturity of the fish.

It would be a good idea to apply the approach used in this exploratory phase to samples of trout (wild and/or farmed) of known genotype and sex from more diverse habitats.

Finally, it could be of interest to find out whether simultaneously using three different methods: geometric morphometrics, conventional morphometrics and the analysis of the meristic and ornamental characteristics (markings and color of the skin) could help to identify genotypes on the basis of phenotypes.

Acknowledgements. This study was carried out as part of an INTERREG IIIA ALCOTRA program named: Identification, conservation and rehabilitation of autochtonous brown trout populations in Haute-Savoie (France) and in the Val d'Aosta (Italy). We would like to express our grateful thanks to C.R. Largiader (University of Berne) during his post-doctoral period at INRA fish genetics laboratory of Jouy-en-Josas, Steven Cadrin and one anonymous referee for offering helpful suggestions.

\section{References}

Adams D.C., Rohlf F.J., Slice D.E., 2004, Geometric morphometrics: Ten years of progress following the "Revolution". Ital. J. Zool. 71, 5-16.

Beacham T.D., 1984, Age and morphology of Chum Salmon in Southern British Columbia. Trans. Am. Fish. Soc. 113, 727-736.

Beacham T.D., Whithler R.E., Murray C.B., Barner L.W., 1988, Variation in body size, morphology, egg size, and biochemical genetics of Pink Salmon in British Columbia. Trans. Am. Fish. Soc. 117, 109-126.

Bookstein F.L., 1991, Morphometric tools for landmark data: geometry and biology. New York, Cambridge University Press. 
Cadrin S.X., 2000, Advances in morphometric identification of fishery stocks. Rev. Fish Biol. Fish. 10, 91-112.

Currens K.P., Shape C.S., Hjort R., Schreck C.B., Li H.W., 1989, Effect of different feeding regimes on the morphometric of chinook salmon (Oncorhynchus tshawytscha) and rainbow trout (O. mykiss). Copeia, 689-695.

Davidson F.A., 1935, The development of secondary sexual characters in the pink salmon (Oncorhynchus kisutch). J. Morphol. 57, 169-183.

Dryden I., Mardia K., 1999, Statistical Shape Analysis. Paris, Lavoisier.

Fleming I.A., Gros M.R., 1989, Evolution of adult female life history and morphology in a Pacific salmon coho (Oncorhynchus kisutch). Evolution 43, 141-157.

Fleming I.A., Jonsson B., Gross M.R., 1994, Phenotypic divergence of sea-ranched, farmed and wild salmon. Can. J. Fish. Aquat. Sci. 51, 2808-2824.

Gardner A.S., Walker A.F., Greer R.B., 1988, Morphometric analysis of two ecologically distinct forms of Arctic charr, Salvelinus alpinus, in Loch Rannoch, Scotland. J. Fish Biol. 32, 901-910.

Gilason D., Ferguson M.M., Skulasson S., Snorrason S.S., 1999, Rapid and coupled phenotypic and genetic divergence in Icelandic Arctic char (Salvelinus alpinus). Can. J. Fish. Aquat. Sci. 56, 2229-2234.

Gjerde B., Schaeffer L.R., 1989, Body traits in rainbow trout. II Estimates of heritabilities and of phenotypic and genetic correlations. Aquaculture 80, 25-44.

Holtby L.B., Swain D.P., Allan G.M., 1993, Mirror-elictic behaviour and body morphology as predictors of dominance status in juvenile Coho Salmon (Oncorhynchus kisutch). Can. J. Fish. Aquat. Sci. 50, 676-684.

Imre I., McLauhlin R.L., Noakes D.L.G., 2002, Phenotypic plasticity in Brook charr: changes in caudal fin induced by water flow. J. Fish Biol. 61, 1171-1181.

Lascaux J.M., 1996, Analyse de la variabilité morphologique de la truite commune (Salmo trutta) dans les cours d'eau du bassin pyrénéen méditerranéen. Thèse Doctorat Sciences Agronomiques. Institut National Polytechnique de Toulouse.

Martin W.R., 1949, The mechanics of environmental control of body form in fishes. Univ. Toronto, Stud., Biol. Ser. 58; Publ. Ontario Fish. Res. Lab. 70.

McLaughlin R.L., Grant J.W.A., 1994, Morphological and behavioural differences among recently-emerged brook charr, Salvelinus fontinalis, foraging in slow-vs. fast-running water. Environ. Biol. Fishes 39, 289-300.

Petersson E., Jarvi T., Olsen H., Mayer I., Hedenskog M., 1999, Matemale competition and female choice in brown trout. Anim. Behav. 57, 777-783.
Quinn T.P., Foote C.J., 1994, The effects of body size and the sexual dimorphism on the reproductive behaviour of sockeye salmon, Oncorhynchus nerka. Anim. Behav. 48, 751-761.

Reyes-Gavilan F.G., Ojanguren A.F., Brana. F., 1997, The ontogenic development of body segments and sexual dimorphism in brown trout (Salmo trutta L.). Can. J. Zool. 75, 651-655.

Riddell B.E., Leggett W.C., 1981, Evidence of an adaptative basis for geographic variation of body morphology and time of downstream migration of juvenile Atlantic salmon (Salmo salar). Can. J. Fish. Aquat. Sci. 38, 308-320.

Riddell B.E., Leggett W.C., Saunders R.L., 1981, Evidence of adaptative polygenic variation between two populations of Atlantic salmon (Salmo salar) native to tributaries of the S.W. Miramichi River N.B. Can. J. Fish. Aquat. Sci. 38, 321-333.

Rohlf F.J., 1990, Rotational fit (Procrustes) methods. In: Rolf, Bookstein F.L. (Eds.) Proceedings of the Michigan Morphometric Workshop. Ann Arbor Univ. Mich. Mus. Zool. Spec. Publ. 2, pp. 227-236.

Rohlf F.J., 1999, Procrustes superimposition and tangent spaces. J. Classification 16, 197-223

Rohlf F.J., Marcus L.F., 1993, A revolution in morphometrics. Trends Ecol. Evol. 8, 129-132.

Skulason S., Snorrason S.S., Jonsson B. 1999, Sympatric morphs, populations and speciation in freshwater fish with emphasis on Arctic charr. In: Magurran A.E., May R. (Eds.) Evolution of biological diversity. Oxford University Press, Oxford UK.

Swain D.P., Holtby L.B., 1989, Differences in morphology and behavior between juvenile coho salmon (Oncorhynchus kisutch) rearing in a lake and its tributary system. Can. J. Fish. Aquat. Sci. 46, 1406-1414.

Taylor E.B., McPhail D.C., 1985, Variation in body morphology among British Columbia populations of coho salmon (Oncorhynchus kisutch). Can. J. Fish. Aquat. Sci. 42, 2020-2028.

Taylor E.B., 1991, A review of local adaptation in Salmoninae, with particular reference to Pacific and Atlantic salmon. Aquaculture 98, 185-207.

Tchernavin V., 1938, Changes in the salmon skull. Trans. Zool. Soc. Lond. 24, 104-184.

Valentin A., Sevigny J.-M., Chanut J.-P., 2002, Geometric morphometrics reveals body shape differences between sympatric redfish Sebastes mentella, Sebastes fasciatus and their hybrids in the Gulf of St- Lawrence. J. Fish Biol. 60, 857-875.

Vladikov V.D., 1962, Osteological studies of Pacific salmon of the genus Oncorhynchus. Fish. Res. Board Bull. 136.

Winans G.A., 1984, Multivariate morphometric variability in Pacific Salmon: technical demonstration. Can. J. Fish. Aquat. Sci. 41, 1150-1159. 